\title{
Enhancement of photoelectrocatalytic degradation of diclofenac with persulfate activated by $\mathrm{Cu}$ cathode
}

\author{
Shanshan Liu ${ }^{\mathrm{a}, \mathrm{b}}$, Xu Zhao ${ }^{\mathrm{a}, *}$, Huabin Zeng ${ }^{\mathrm{a}, \mathrm{b}}$, Yanbin Wang ${ }^{\mathrm{a}}$, Meng Qiao ${ }^{\mathrm{a}}$, Wei Guan ${ }^{\mathrm{a}, \mathrm{c}}$ \\ ${ }^{a}$ Key Laboratory of Drinking Water Science and Technology, Research Center for Eco-Environmental Sciences, Chinese Academy of Sciences, Beijing 100085, China \\ ${ }^{\mathrm{b}}$ University of Chinese Academy of Sciences, Beijing 100049, China \\ ${ }^{\mathrm{c}}$ Chongqing Key Laboratory of Environmental Materials E Remediation Technologies, Chongqing University of Arts and Sciences, Chongqing 402160, China
}

\section{H I G H L I G H T S}

- Photoelectro-oxidation of diclofenac was largely enhanced with persulfate addition.

- $\mathrm{Cu}_{2} \mathrm{O}$ was identified at copper cathode by in situ Raman technique.

- Activation mechanism of persulfate

to $\mathrm{SO}_{4}^{--}$at copper cathode was proposed.
G R A P H I C A L A B S T R A C T

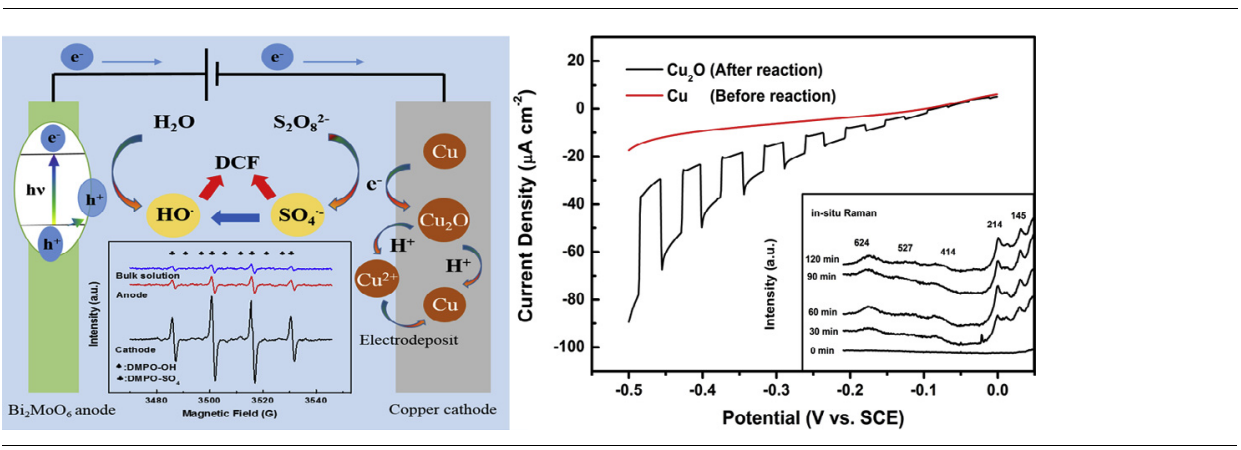

\begin{abstract}
A B S T R A C T
In this work, persulfate $\left(\mathrm{S}_{2} \mathrm{O}_{8}^{2-}, \mathrm{PS}\right)$ was introduced to the photoelectrocatalytic (PEC) system, which consisted of a $\gamma-\mathrm{Bi}_{2} \mathrm{MoO}_{6}$ photoanode and a copper foil cathode $\left(\mathrm{Bi}_{2} \mathrm{MoO}_{6} / \mathrm{Cu} / \mathrm{PEC} / \mathrm{PS}\right.$ system). Significant enhancement of diclofenac sodium (DCF) degradation efficiency was observed in this system under visible light irradiation. At an applied bias of $1.5 \mathrm{~V}$ and initial solution $\mathrm{pH}$ of 5.62, the removal efficiency of DCF with an initial concentration of $10 \mathrm{mg} / \mathrm{L}$ was increased from $19.4 \%$ in the PEC process to $86.3 \%$ in the PEC process with $10 \mathrm{mM}$ PS addition. The pseudo-first-order kinetic rate constant of DCF degradation was increased from $0.1112 \mathrm{~h}^{-1}$ to $1.0498 \mathrm{~h}^{-1}$. Active free radicals involving $\mathrm{SO}_{4}^{--}$and $\mathrm{HO}$ - were produced in this process, which were confirmed by electron spin resonance analysis. Furthermore, the surface variation of copper foil cathode was characterized by FE-SEM, GI-XRD, XPS and in situ Raman spectroscopy. It was demonstrated that $\mathrm{Cu}_{2} \mathrm{O}$ formed on the surface in the reaction process with the $\mathrm{S}_{2} \mathrm{O}_{8}^{2-}$ addition, which was further confirmed by the photoelectrochemical analysis of the cathode. The surface $\mathrm{Cu}(0)-\mathrm{Cu}(\mathrm{I})-\mathrm{Cu}(\mathrm{II})-\mathrm{Cu}(0)$ redox cycle of cathode was proposed, which was responsible for the persulfate activation, leading to the generation of free radicals. This work may provide a new perspective on the combined utilization of different technologies for catalytic contaminant removal.
\end{abstract}

(c) 2017 Published by Elsevier B.V.

\section{Introduction}

Pharmaceuticals and personal care products (PPCPs) have received an increasing attention of their occurrence and transfer

\footnotetext{
* Corresponding author at: P.O. Box 2871, 18 Shuangqing Road, Haidian District, Beijing 100085, PR China.

E-mail address: zhaoxu@rcees.ac.cn (X. Zhao).
}

in aquatic systems and soils over the past few years [1,2]. Diclofenac sodium (DCF), which is considered as a common non-steroidal anti-inflammatory drug and meanwhile, a persistent toxic pollutant, may produce adverse effect on animal kidney, liver and cause renal lesions $[3,4]$. Due to its low biodegradability, DCF cannot be effectively removed by conventional biochemical processes [5]. In recent years, the application of $\mathrm{UV}, \mathrm{UV} / \mathrm{H}_{2} \mathrm{O}_{2}$ and ozonation treatments in its degradation was largely investigated. For instance, it 
has been proved that DCF could be removed effectively by UV irradiation with $\mathrm{H}_{2} \mathrm{O}_{2}$ addition [2,6], and ozonation technology also achieved a complete conversion of chlorine to ions and 32\% mineralization of DCF for $1.5 \mathrm{~h}$ treatment [7].

Photoelectrocatalytic (PEC) oxidation process in which a small positive potential is applied on the semiconductor photoanode has proven to be more efficient than single photocatalytic process [8]. In PEC system, the application of a small external bias decreases the recombination rate of photogenerated electronhole pairs and thus increases the photocatalytic activity of the semiconductor photocatalyst [9]. It has been largely investigated on the application of PEC processes in degrading refractory organics in aquatic system and water splitting recently [10]. In a PEC system, the semiconductor film electrode is usually used as the photoanode for organics oxidation, while the role of the cathode beyond a counter electrode is not fully exploited. Studies about cathode utilization such as reticulated vitreous carbon as a counter electrode for $\mathrm{H}_{2} \mathrm{O}_{2}$ generation to enhance PEC oxidation were reported [11]. But the amount of generated $\mathrm{H}_{2} \mathrm{O}_{2}$ via the cathodic reduction is limited due to the low applied bias used in PEC system. Therefore, it is desired to simultaneously improve the oxidation efficiency of organic contaminants and cathode utilization in the PEC system.

Recently, sulfate radical $\left(\mathrm{SO}_{4}^{-}\right)$based processes have been paid more attention on the removal of organic contaminants. It has been proved that persulfate $\left(\mathrm{S}_{2} \mathrm{O}_{8}^{2-}\right.$, PS) can be activated to generate sulfate radicals with a redox potential of $2.5 \sim 3.1 \mathrm{~V}$ which can efficiently decompose organics in water [12]. Generally, persulfate can be activated by physical means such as heating [13], UV irradiation [14] and microwave [15] as shown in Eq. (1).

$\mathrm{S}_{2} \mathrm{O}_{8}^{2-}+$ Heat/hv/Microwave $\rightarrow 2 \mathrm{SO}_{4}^{-}$

Driven by the need of overcoming the drawback of above physical means, transition metal activation (Eq. (2)) has an advantage on high efficiency without high energy consumption and could be achieved under room temperature. For example, $\mathrm{Fe}(0)$ [16], Fe (II) [17] and $\mathrm{Ag}(\mathrm{I})$ [18] could be used as PS activators.

$\mathrm{S}_{2} \mathrm{O}_{8}^{2-}+\mathrm{M}^{\mathrm{n}+} \rightarrow \mathrm{SO}_{4}^{--}+\mathrm{SO}_{4}^{2-}+\mathrm{M}^{\mathrm{n}+1}$

Owing to its rich abundance and high catalytic efficiency, copperbased catalyst has attracted a particular attention nowadays. PS activation by copper ion was proven to be efficient for propachlor degradation [19]. Zhang et al. discovered that magnetic $\mathrm{CuFe}_{2} \mathrm{O}_{4}$ spinel showed high activity on inducing peroxymonosulfate (PMS) activation; iopromide as target contaminant can be removed completely within $10 \mathrm{~min}$ at the PMS dosage of $20 \mu \mathrm{M}$ [20]. It was also reported that almost $100 \%$ phenol was removed in $120 \mathrm{~min}$ with addition of $5 \mathrm{mM}$ PS and $0.3 \mathrm{~g} / \mathrm{L} \mathrm{CuO}-\mathrm{Fe}_{3} \mathrm{O}_{4}$ composite catalyst [21]. Above studies propose that the $\mathrm{Cu}(\mathrm{II})-\mathrm{Cu}(\mathrm{III})-\mathrm{Cu}(\mathrm{II})$ redox cycle activates PS to form free radicals. However, Zhang suggested that peroxydisulfate (PDS) activation can be achieved not relying on sulfate radical generation but electrons rearrangement of PDS [22]. These results indicate the high efficiency of copper-based catalysts for the PS activation through different mechanisms.

To further improve the contaminant degradation efficiency, above two techniques are considered to be combined. Fu et al. investigated the response surface methodology (RSM) on optimising the photoelectrocatalytic degradation of fulvic acid (FA) [23]. A. A. El-Zomrawy reported photoelectrocatalytic degradation of dye with ammonium persulfate (APS) addition [24]. However, the mechanism remained unclear about the interaction between PS and PEC reaction. Zeng et al. reported that PS was added to a photoelectrocatalytic system driven by UV light in order to enhance the $\mathrm{Cu}$-EDTA decomplexation and $\mathrm{Cu}$ recovery [25]. This paper indicated the PS activation through cathodic electron and served as a bridge between two techniques. To the best of our knowledge, there have been no published work about the PS activation through cathode itself in PEC system under visible light irradiation.

Herein, $\mathrm{Cu}$ cathode was used in a PEC system to activate PS and to improve the PEC degradation efficiency of target contaminant, DCF. In situ Raman spectroscopy combined with photoelectrochemical analysis was employed to analyze the copper cathode variation and generation of $\mathrm{Cu}_{2} \mathrm{O}$ on the surface was confirmed. The variation of copper species was investigated in detail. In this variation process, PS was activated and free radicals such as HOand $\mathrm{SO}_{4}^{--}$were produced, which were responsible for the enhanced degradation efficiency of DCF. The activation mechanism was investigated in details.

\section{Material and methods}

\subsection{Chemicals}

Sodium persulfate $\left(\mathrm{Na}_{2} \mathrm{~S}_{2} \mathrm{O}_{8}, 98+\%\right.$ purity) and sodium sulfite $\left(\mathrm{Na}_{2} \mathrm{SO}_{3}, 98.5 \%\right.$ purity) were bought from Acros Organics. Diclofenac sodium $\left(\mathrm{C}_{14} \mathrm{H}_{10} \mathrm{Cl}_{2} \mathrm{NNaO}_{2}, 98 \%\right.$ purity) was procured from TOKYO Chemical Industry Co.,Ltd. Sodium sulfate $\left(\mathrm{Na}_{2} \mathrm{SO}_{4}, 99 \%\right.$ purity), Bismuth(III) nitrate pentahydrate $\left(\mathrm{Bi}\left(\mathrm{NO}_{3}\right)_{3} \cdot 5 \mathrm{H}_{2} \mathrm{O}, 99 \%\right.$ purity), Molybdenum oxide $\left(\mathrm{MoO}_{3}, 99.5 \%\right.$ purity), Diethylenetriaminepentaacetic acid $\left(\mathrm{C}_{14} \mathrm{H}_{23} \mathrm{~N}_{3} \mathrm{O}_{10}, 99.0+\%\right.$ purity $)$, Diethanolamine $\left(\mathrm{C}_{4} \mathrm{H}_{11} \mathrm{NO}_{2}, 98-102 \%\right.$ purity), sodium acetate $\left(\mathrm{CH}_{3} \mathrm{COONa}\right.$, $99 \%$ purity) and acetic acid $\left(\mathrm{CH}_{3} \mathrm{COOH}, 99.8 \%\right.$ purity) were all purchased from Sinopharm Chemical Reagent Co.,Ltd. The 5,5-dimethyl-1pyrrolidine N-oxide (DMPO) was obtained from Aladdin, China. The copper foil was bought from Beijing Heng Li Ti Co.,Ltd. All reagents used were at least analytical grade and without further purification. All solutions were prepared to required concentration in Milli-Q water $(\rho=18.2 \mathrm{M} \Omega \cdot \mathrm{cm})$.

\subsection{Experimental section}

Degradation experiments were carried out in a rectangular quartz reactor with DCF solution $(120 \mathrm{~mL}, 10 \mathrm{mg} / \mathrm{L})$. The PEC reaction was driven by an electrochemical workstation (CHI 660E; Shanghai Chenhua Instruments Co.,Ltd, Shanghai, China) connected with a working photoelectrode (the $\gamma-\mathrm{Bi}_{2} \mathrm{MoO}_{6}$ film deposited onto the Indium-tin oxide glass, active area of $13 \mathrm{~cm}^{2}$ ), a counter electrode (copper foil, active area of $13 \mathrm{~cm}^{2}$ ) and a reference electrode (saturated calomel electrode). The visible light source was from a Xe lamp (PLS-SXE300; Beijing PerfectLight Co., Ltd, Beijing, China) with a UV cutoff filter $(\lambda>420 \mathrm{~nm})$. Linear sweep voltammetry (LSV) was also conducted in a singlecompartment with $\mathrm{Na}_{2} \mathrm{SO}_{4}$ electrolyte, three electrode cell on the same workstation. Electrochemical impedance spectra (EIS, presented in Supplementary material) were measured at $0 \mathrm{~V}$ (vs. open circuit potential) on an electrochemical workstation (Interface 1000, Gamry, America). The initial $\mathrm{pH}\left(\mathrm{pH}_{0}\right)$ adjustments were achieved by moderate addition of $\mathrm{H}_{2} \mathrm{SO}_{4}(0.1 \mathrm{M})$ or $\mathrm{NaOH}(0.1 \mathrm{M})$. Samples were taken from the reactor every $30 \mathrm{~min}$ and filtered through $0.22 \mu \mathrm{m}$ membrane prior to analysis.

As reported in our previous work [26], $\gamma-\mathrm{Bi}_{2} \mathrm{MoO}_{6}$ film was deposited onto indium tin oxide (ITO) substrate from an amorphous heteronuclear complex solution by dip-coating method. Before each experiment, the anode film was rinsed by Milli-Q water and the copper foil used as a cathode was rinsed by hydrochloric acid, cleaned with 800-grit sandpapers to remove any rusts or solid deposits and double rinsed with Milli-Q water. 


\subsection{Analytical procedures}

The concentration of DCF was determined by high performance liquid chromatography (HPLC; Shimadzu LC-20AT, Tokyo, Japan) with a $\mathrm{C} 18(250 \mathrm{~mm} \times 4.6 \mathrm{~mm} \times 5 \mu \mathrm{m})$ reversed-phase column (GL Sciences Inc., Tokyo, Japan) and a UV detector. The mobile phase was a mixture of acetate buffer $(\mathrm{pH}=5.0)$ and methanol $(\mathrm{V} / \mathrm{V}=40 / 60)$ with a flow rate of $1 \mathrm{~mL} / \mathrm{min}$. The injection volume was set as $20 \mu \mathrm{L}$.

For the intermediates identification, samples were filtered and analyzed by UPLC-Q-TOF-MS (ACQUITY UPLC, Quattro Premier $\mathrm{XE}$, Waters, America) with $\mathrm{C} 18(50 \mathrm{~mm} \times 2.1 \mathrm{~mm} \times 1.7 \mu \mathrm{m})$ reversed-phase column. The mobile phase contained $A(0.2 \%$ formic acid in water) and B ( $0.1 \%$ formic acid in acetonitrile) at the flow rate of $0.3 \mathrm{~mL} / \mathrm{min}$. The gradient was $90 \% \mathrm{~A}$ for $1 \mathrm{~min}$, linearly increasing to $95 \%$ B for $8 \mathrm{~min}, 95 \% \mathrm{~B}$ and $5 \%$ A for $5 \mathrm{~min}$, decreasing back to $90 \%$ A and maintaining for $1 \mathrm{~min}$. The mass spectrometer was operated with negative electrospray ionization recorded from 50 to $1000 \mathrm{~m} / \mathrm{z}$.

The mineralization of DCF was measured with an Elementar vario TOC analyzer (Germany). The $\mathrm{pH}$ adjustment was completed on PHS-3E. The metal ions were quantified by inductively coupled plasma-optical emission spectrometer (ICP-OES, Optima 8300, PerkinElmer, America).

The surface morphology of electrodes was characterized by field emission-scanning electron microscope (FE-SEM; HITACHI SU8020, Tokyo, Japan). The X-ray diffraction (XRD) patterns of electrodes were recorded on an X-ray diffractometer (XPert Pro MPD) with a $\mathrm{Cu} \mathrm{K} \alpha$ radiation. X-ray photoelectron spectroscopy (XPS) was measured on ESCALAB 250Xi (Thermo Fisher Scientific) to determine the chemical state of copper. In situ Raman spectroscopic studies were performed with a confocal Raman microscope (LabRAM HR 800, Horiba, Tokyo, Japan), equipped with an Ar laser $(514 \mathrm{~nm})$ and a $40 \times$ objective.

For the involved radical studies, experiments were detected on Bruker A300-10/12 (Germany) using DMPO as trapping agent. The measurements were conducted using a radiation of $9.85 \mathrm{GHz}$ (X band) with center field of $3512.170 \mathrm{G}$, modulation frequency of $100 \mathrm{kHz}$, sweep width of $200 \mathrm{G}$, sweep time of $81.92 \mathrm{~s}$, time constant of $40.96 \mathrm{~ms}$, and microwave power of $21 \mathrm{MW}$ at room temperature.

\section{Results and discussion}

\subsection{Characterization of $\gamma-\mathrm{Bi}_{2} \mathrm{MoO}_{6}$ film anode}

XRD pattern and SEM image of $\gamma-\mathrm{Bi}_{2} \mathrm{MoO}_{6}$ were shown in Fig. 1 (a). The peaks of prepared electrode are in conformity with the standard $\mathrm{Bi}_{2} \mathrm{MoO}_{6}$ (JCPDS: 21-0102). Both the sharpness of XRD reflections and small half peak width clearly demonstrate that the synthesized $\gamma-\mathrm{Bi}_{2} \mathrm{MoO}_{6}$ film is highly crystalline. The cell parameters are $\mathrm{a}=5.50 \AA \mathrm{b}=16.24 \AA \mathrm{c}=5.49 \AA$ and the principal crystalline phase is orthorhombic structure. As Fig. 1(a) inset graph shows, the film consists of small particles with a porous structure. In recent years, Bi-based photocatalysts are getting more and more attention $[27,28]$. The electrochemical behavior of photoanode was also investigated by LSV in solution with $0.05 \mathrm{M} \mathrm{Na}_{2} \mathrm{SO}_{4}$ at a potential range from $0.0 \mathrm{~V}$ to $1.5 \mathrm{~V}$ (vs. SCE). As shown in Fig. 1(b), the $\mathrm{Bi}_{2} \mathrm{MoO}_{6}$ electrode shows a strong photocurrent under visible light irradiation. The transient photocurrent response of prepared $\mathrm{Bi}_{2} \mathrm{MoO}_{6}$ electrode was examined. As shown in Fig. 1(c), the photocurrent with good reproducibility for prepared photoanode is observed when irradiated by visible light. After several cycles, the current remains stable and this indicates that the electrode photoresponse is repeatable and reversible. Under $1 \mathrm{~V}$ applied bias,
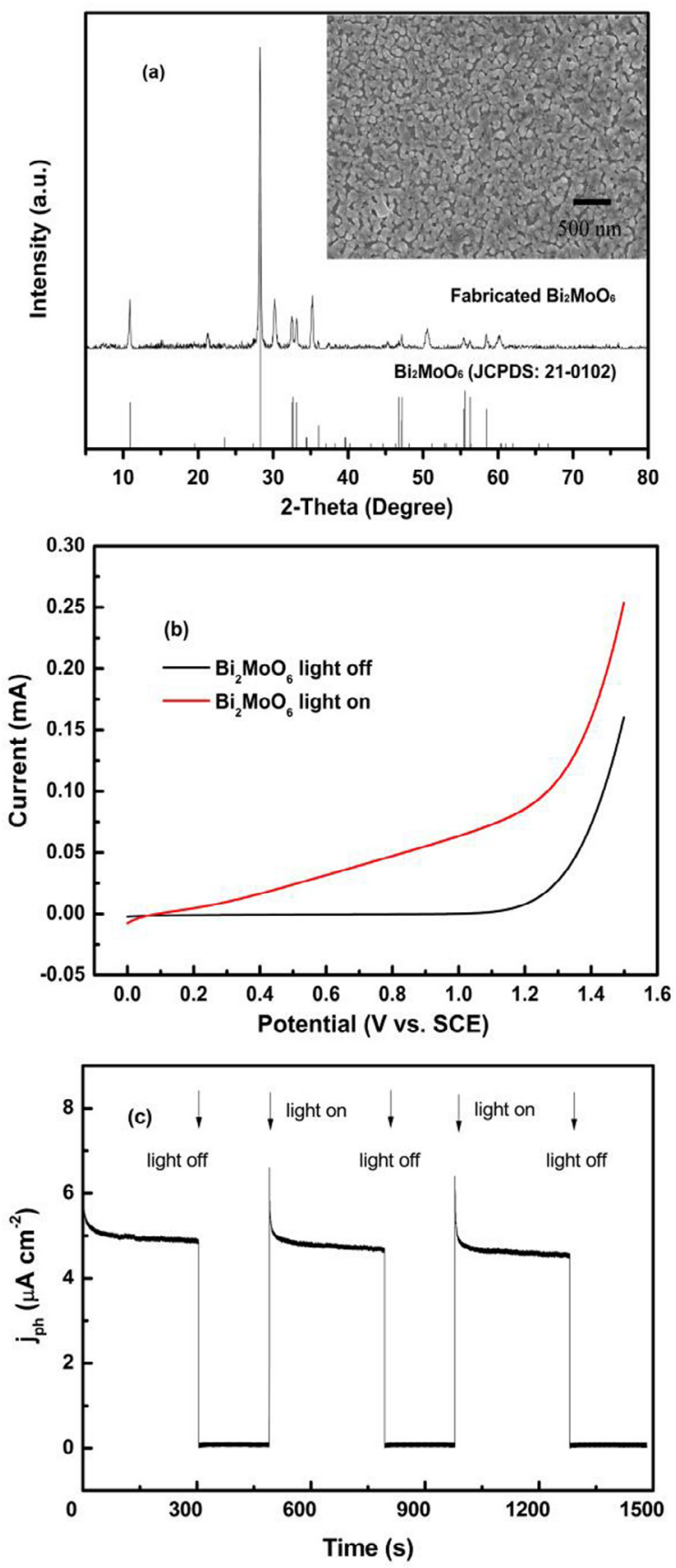

Fig. 1. XRD pattern and SEM image (inset) (a), LSV curves at a potential range of 0.0 to $1.5 \mathrm{~V}$ (vs. SCE) (b) and the transient photocurrent response (c) of the prepared $\mathrm{Bi}_{2} \mathrm{MoO}_{6}$ electrode. Conditions: $\left[\mathrm{Na}_{2} \mathrm{SO}_{4}\right]=0.05 \mathrm{M}, \lambda>420 \mathrm{~nm}$.

the photocurrent density of electrode is $5 \mu \mathrm{A} \cdot \mathrm{cm}^{-2}$. The optical property of prepared anode was conducted by UV-Vis diffuse reflectance spectroscopy and presented in Supplementary material (Fig. S1). The bandgap of the prepared $\gamma-\mathrm{Bi}_{2} \mathrm{MoO}_{6}$ is determined to be $2.58 \mathrm{eV}$ and it exhibits a strong ability to utilize the visible portion of solar spectrum. The above result demonstrated that the prepared photoanode represented a good response to visible light.

\subsection{Enhancement performance for DCF degradation}

As shown in Fig. 2(a), only 19.4\% of DCF is removed in $2 \mathrm{~h}$ in the PEC system using $\mathrm{Bi}_{2} \mathrm{MoO}_{6}$ as photoanode and $\mathrm{Cu}$ as cathode, and 

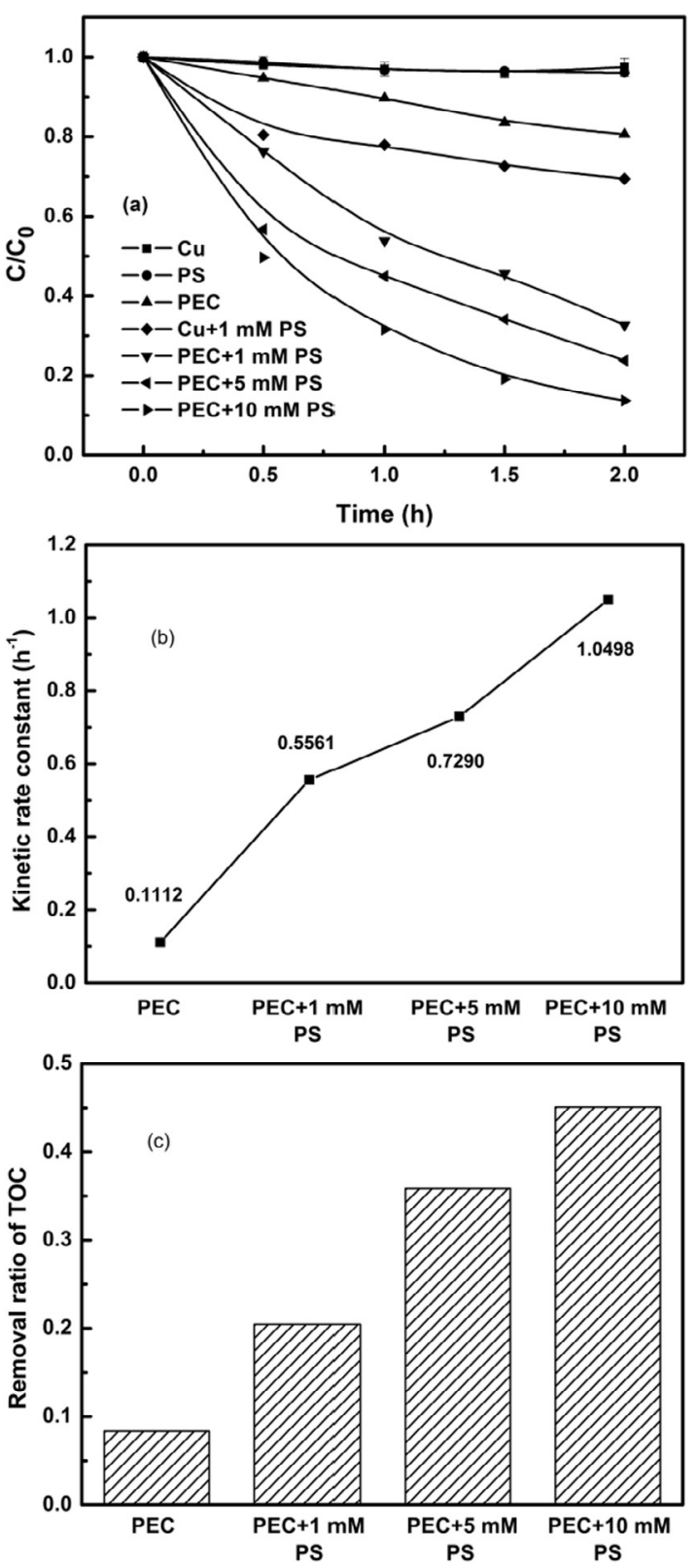

Fig. 2. Effect of PS concentration on the DCF removal (a), kinetic rate constants (b) and removal ratio of TOC (c). Conditions: $[D C F]=10 \mathrm{mg} / \mathrm{L}$; applied bias, $1.5 \mathrm{~V}$; $\mathrm{pH}_{0}, 5.62$.

the removal efficiency of DCF by PS or copper alone is negligible. When copper itself is put into the solution with $1 \mathrm{mM} \mathrm{PS}, 30.6 \%$ of DCF is removed. Interestingly, a remarkable enhancement of DCF removal is observed with the addition of $1 \mathrm{mM}$ PS into the PEC process, and nearly 70\% DCF is removed in $2 \mathrm{~h}$. Meanwhile, the effect of PS concentration on the DCF degradation was examined. It is observed that the removal efficiency of DCF increases with the PS concentration. With $10 \mathrm{mM}$ PS, 86.3\% DCF is removed. All these results indicate that the combination of PS and PEC process is an efficient way to degrade the target contaminant from water.

The kinetic investigations exhibit that the degradation reaction of DCF follows a pseudo-first-order kinetics equation and the rate constant versus the concentration of PS is shown in Fig. 2(b). It is estimated to be $0.1112 h^{-1}\left(R^{2}=0.993\right)$ in the PEC system without the addition of PS. By contrast, corresponding to PS concentration of 1,5 and $10 \mathrm{mM}$, the rate constants are $0.5561 \mathrm{~h}^{-1}\left(\mathrm{R}^{2}=0.992\right)$,
$0.7290 h^{-1}\left(R^{2}=0.995\right)$ and $1.0498 h^{-1}\left(R^{2}=0.987\right)$, respectively. These results strongly confirm the enhancement of DCF degradation efficiency in PEC process with the PS addition.

With respect to TOC variation, in PEC system, the TOC removal ratio is less than $10 \%$. As shown in Fig. 2(c), when 1, 5 and $10 \mathrm{mM}$ PS is added to the solution, it increases to $20.5 \%, 35.9 \%$ and $45.1 \%$, respectively. It is demonstrated that DCF can be degraded more thoroughly in the PEC process with an increasing addition of PS.

\subsection{Influence of applied bias and initial $\mathrm{pH}$}

The effect of applied bias on the DCF removal in PEC process was investigated with $1 \mathrm{mM}$ PS addition. As illustrated in Fig. 3(a), the degradation efficiency of DCF increases with the increasing applied potential. For example, when the applied bias increases from $0 \mathrm{~V}$ to $0.5 \mathrm{~V}$, the removal ratio of DCF increases from $17.3 \%$ to $25.3 \%$. As the potential is increased to $2 \mathrm{~V}$, a $72.4 \%$ removal of DCF is achieved within $2 \mathrm{~h}$. It can be seen from Fig. 3(b) that the kinetic rate constant increases as the applied bias increases. When the applied bias increases from $0 \mathrm{~V}$ to $2 \mathrm{~V}$, the rate constant increases from $0.0912 \mathrm{~h}^{-1}\left(\mathrm{R}^{2}=0.980\right)$ to $0.6431 \mathrm{~h}^{-1}\left(\mathrm{R}^{2}=0.990\right)$.

The increased degradation efficiency is due to firstly, the increased bias promotes the separation of the photogenerated electron-hole pairs and reduces their recombination possibility [29]. As a result, the photocatalytic oxidation of DCF at the photoanode is increased $[30,31]$. Secondly, as shown in Fig. 3(c), the copper concentration in the solution decreases obviously when the applied bias increases to be $2 \mathrm{~V}$. It is clear that the increased applied bias is beneficial to the cathodic reduction of the liberated copper ions in PEC system within a certain range. The $\mathrm{Cu}$ cathodic leakage and reduction in the long-term run was also evaluated (Text S1, Fig. S2).

The effect of $\mathrm{pH}_{0}$ on the DCF removal and solution $\mathrm{pH}$ variation in the PEC process were illustrated in Fig. 4. As shown in Fig. 4(a), when the $\mathrm{pH}_{0}$ increases from $5.62,7.00$ to 10.00 , the removal ratio of DCF decreases from $67.4 \%, 64.5 \%$ to $46.3 \%$ at $2 \mathrm{~h}$. As shown in the inset graph of Fig. 4(a), the degradation rate of DCF is well fitted with a pseudo-first-order reaction model at each initial solution $\mathrm{pH}$ and the kinetic rate constants are determined to be $0.5561 \mathrm{~h}^{-1}\left(\mathrm{R}^{2}=0.992\right), 0.4882 \mathrm{~h}^{-1}\left(\mathrm{R}^{2}=0.982\right)$ and $0.3217 \mathrm{~h}^{-1}$ $\left(\mathrm{R}^{2}=0.987\right)$, respectively.

Thus, it is clear that the rate of DCF degradation efficiency decreases with an increase of $\mathrm{pH}_{0}$. DCF has a pKa of 4.0, it deprotonates in the $\mathrm{pH}_{0}$ range of 5.62 to 10.0 thus is always negative charged. Therefore, the effect from the charge interaction between electrode and DCF can be excluded. There may be some other factors which influence the DCF degradation in this system. From the view of free radicals, the redox potential of $\mathrm{SO}_{4}^{--}$is confirmed as $2.5 \sim 3.1 \mathrm{~V}$, even higher than $\mathrm{HO}^{*}$ (potential of HO' is about $2.7 \mathrm{~V}$ in acid solution and $1.8 \mathrm{~V}$ in neutral solution) [32-35]. As shown in Eq. (3), the conversion of $\mathrm{SO}_{4}^{--}$to $\mathrm{HO}$ occurs easily in alkaline conditions [36]. Therefore, more $\mathrm{SO}_{4}^{--}$are generated at acid conditions, which may be partly responsible for the efficient DCF degradation under acid conditions.

$\mathrm{SO}_{4}^{--}+\mathrm{OH}^{-} \rightarrow \mathrm{SO}_{4}^{2-}+\mathrm{HO}^{\cdot} \quad \mathrm{k}=(6.5 \pm 1.0) \times 10^{7} \mathrm{M}^{-1} \mathrm{~s}^{-1}$

Moreover, PS was reported to be further catalyzed under acid conditions according to the literature [37] indicated by Eqs. (4) and (5):

$\mathrm{S}_{2} \mathrm{O}_{8}^{2-}+\mathrm{H}^{+} \rightarrow \mathrm{HS}_{2} \mathrm{O}_{8}^{-}$

$\mathrm{HS}_{2} \mathrm{O}_{8}^{-} \rightarrow \mathrm{SO}_{4}^{--}+\mathrm{SO}_{4}^{2-}+\mathrm{H}^{+}$

On the other hand, solution $\mathrm{pH}$ may affect the generation of $\mathrm{Cu}$ species and the liberation of copper ions in solution. As shown in Fig. 4(b), the leached copper concentration is decreased from acid 

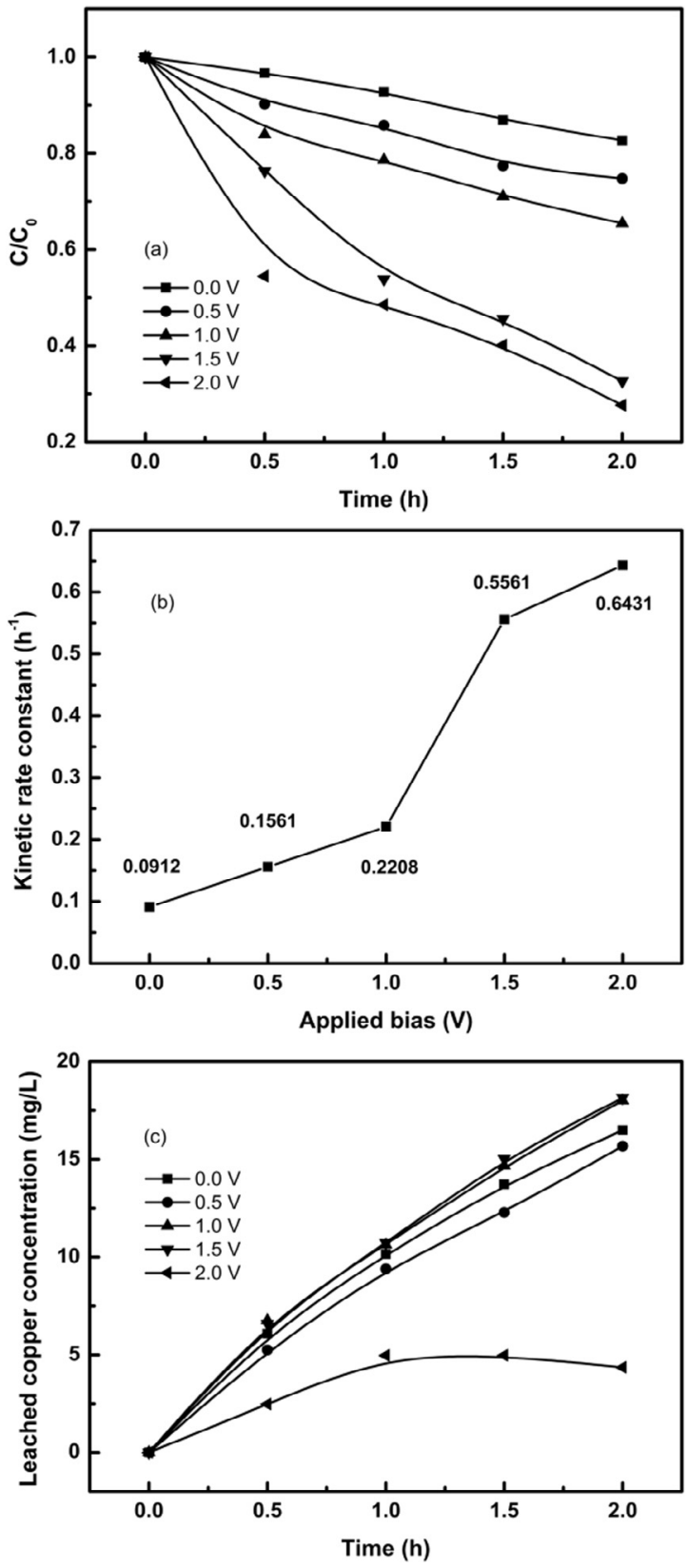

Fig. 3. Effect of applied bias on the DCF removal (a), kinetic rate constants (b) and leached copper concentration (c) in PEC system. Conditions: $[D C F]=10 \mathrm{mg} / \mathrm{L}$; [PS] $=1 \mathrm{mM} ; \mathrm{pH}_{0}, 5.62$.

to alkaline conditions. Copper ions in alkaline conditions are inclined to precipitate. By contrast, acid condition is beneficial to copper electrodeposition [38], which will be discussed subsequently.

The $\mathrm{pH}$ variations with the reaction evolution under different conditions were shown in Fig. 4(c). It can be observed that the solution $\mathrm{pH}$ decreases as the reaction proceeds under both acid and alkaline conditions. This phenomenon is caused by the acidification stems from the transformation of $\mathrm{SO}_{4}^{--}$to $\mathrm{HO}$, which consumes $\mathrm{OH}^{-}$in the solution according to Eq. (3). The result was consistent with the research reported by Gu et al. [37].

\subsection{Involved active radicals}

According to previous literatures [14,22], there are two major proposed mechanisms to explain the PS activation process: radical
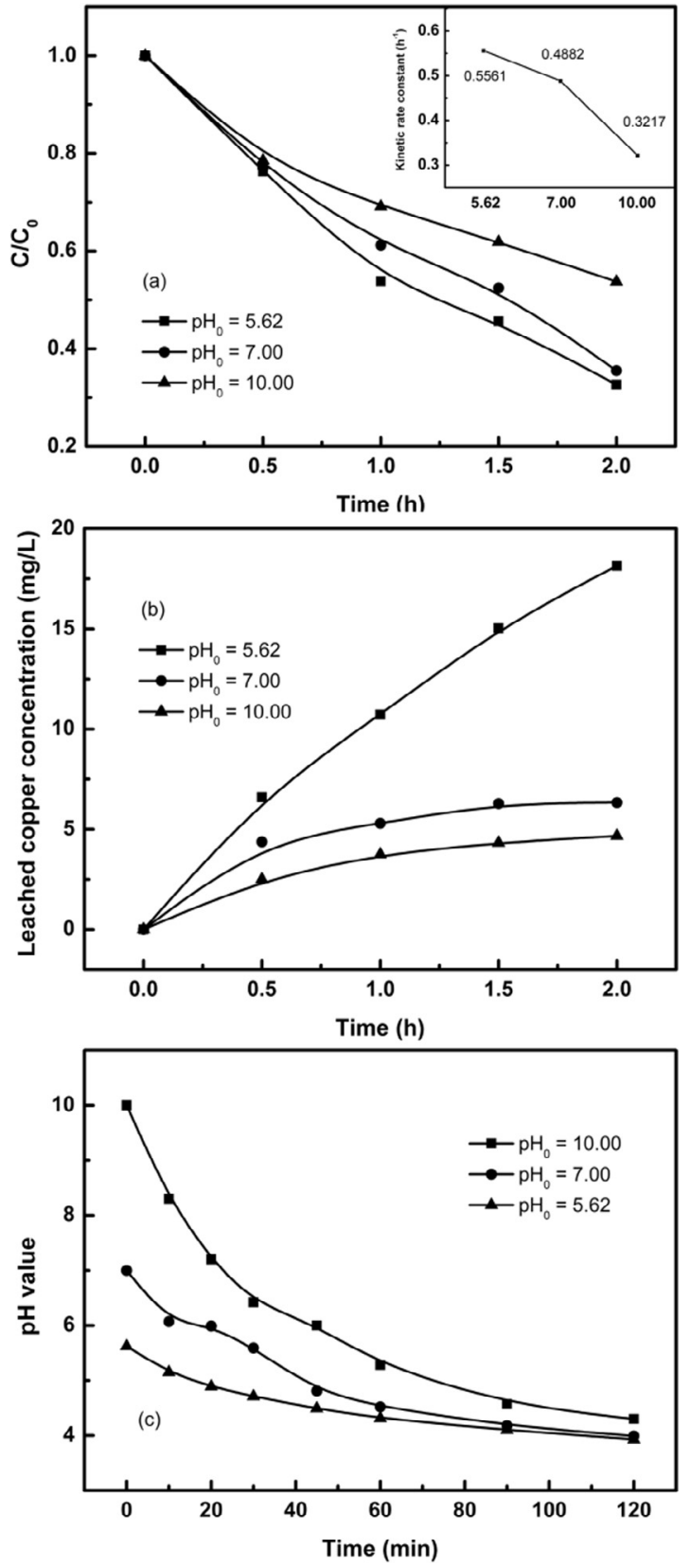

Fig. 4. Effect of $\mathrm{pH}_{0}$ on the DCF removal (a), leached copper ions concentration (b) and $\mathrm{pH}$ variation (c) during the reaction in the PEC system. Conditions: [DCF] $=10 \mathrm{mg} / \mathrm{L} ;$ applied bias, $1.5 \mathrm{~V} ;[\mathrm{PS}]=1 \mathrm{mM}$.

processes and nonradical processes. In most cases, it was illustrated that $\mathrm{SO}_{4}^{--}$and $\mathrm{HO}^{-}$were produced in the process of activation which was responsible for the pollutant degradation [16,39]. As shown in Fig. 5(a), $\mathrm{SO}_{4}^{-}$and $\mathrm{HO}^{-}$are both detected at the $\mathrm{Cu}$ cathode and $\mathrm{Bi}_{2} \mathrm{MoO}_{6}$ anode in our PEC system. In PEC system, the photoanode produces electron-hole pairs and the holes can move to the surface of semiconductor to react with water and form $\mathrm{HO}$ [30]. The detected HO at the anode stem from this process. It can be concluded that the relative intensity of free radicals generated at the cathode is much higher than those generated at the anode and in the bulk solution. The above results indicate that free radicals are produced in this PS activation process and it mainly occurs at the surface of the copper cathode in this PEC system.

In order to investigate the role of $\mathrm{Cu}$ foil cathode in the generation process of free radicals, the control experiments were conducted by using $\mathrm{Ti}, \mathrm{Fe}$ and Co foil as cathodes (the ESR analyses 

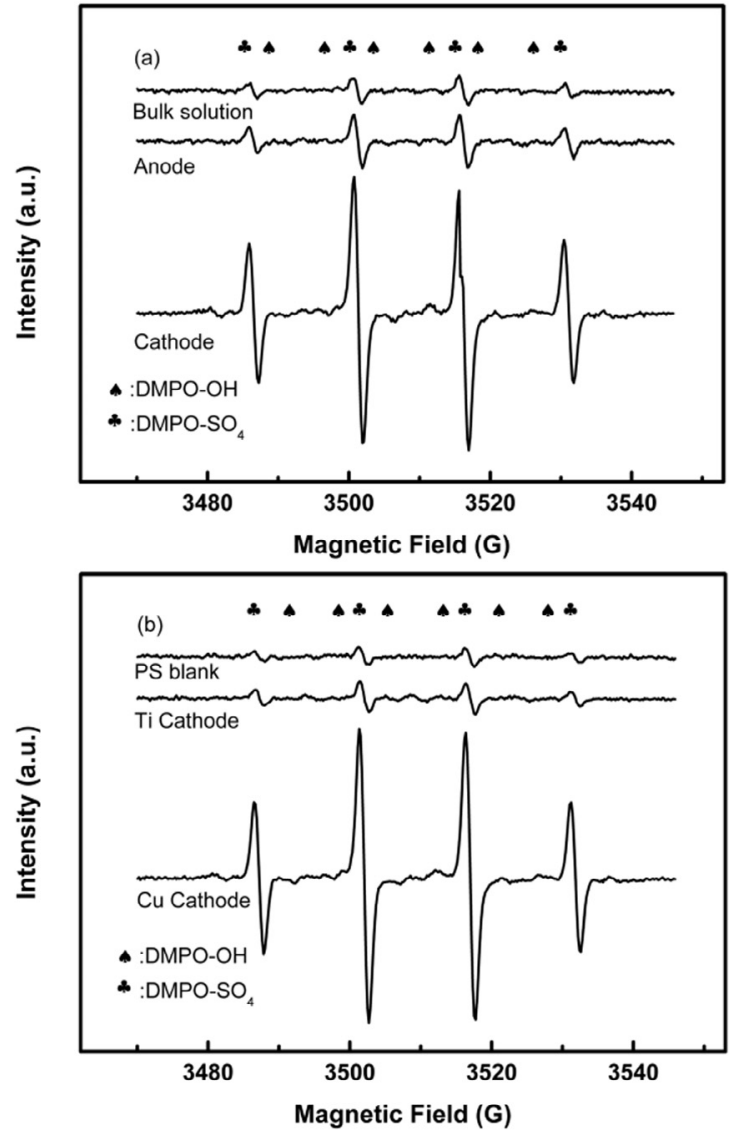

Fig. 5. Comparison of ESR spectrum in bulk solution, at the anode and at the cathode in $\mathrm{Bi}_{2} \mathrm{MoO}_{6} / \mathrm{Cu} / \mathrm{PEC} / \mathrm{PS}$ system (a); Comparison of ESR spectrum in aqueous solution, at Ti cathode and at $\mathrm{Cu}$ cathode in PEC system (b). Conditions: Applied bias, $1.5 \mathrm{~V}$; $[\mathrm{PS}]=5 \mathrm{mM}$; $\mathrm{pH}_{0}, 5.62$.

of Fe, Co cathodes were shown in Fig. S3). As shown in Fig. 5(b), the peak intensities of $\mathrm{HO}^{-}$and $\mathrm{SO}_{4}^{--}$generated at the $\mathrm{Cu}$ cathode are obviously higher than other metal cathodes. Some literatures demonstrate that photogenerated electrons could activate PS in the photocatalytic process $[40,41]$. In our case, the photogenerated electrons transferred to the cathode is limited for activating PS. Meanwhile, the $\mathrm{Cu}$ cathode plays the key role in activating PS. The effects of PS concentration, applied bias and $\mathrm{pH}_{0}$ on ESR signals of $\mathrm{SO}_{4}^{--}$and $\mathrm{HO}^{-}$are further investigated in detail. As illustrated in Fig. S4(a)-(b), as the PS concentration and applied bias increases, the peak intensities of $\mathrm{HO}^{-}$and $\mathrm{SO}_{4}^{--}$at the $\mathrm{Cu}$ cathode increase which leads to an increased degradation efficiency of DCF. As shown in Fig. S4(c), more free radicals may exist in the form of HO- in alkaline conditions according to Eq. (3) as stated.

\subsection{Characterizations of the $\mathrm{Cu}$ cathode variation}

It was noticed that the fresh copper foil cathode became dark red with the addition of PS during the PEC reaction. The surface change of copper cathode was firstly checked using the FE-SEM technique. As shown in Fig. 6, the surface of copper foil is relatively smooth and uniform before the PEC reaction. The scratches observed are caused by copper pretreatment by sandpaper polish. However, the smooth surface is destroyed with the generation of porous structure at the PEC reaction time of 0.5 and $1 \mathrm{~h}$. With the reaction evolution, this structure can be always observed and nearly covers the copper surface fully at $2 \mathrm{~h}$.

Furthermore, copper cathode samples at various times in the PEC reaction with PS addition were analyzed by GI-XRD. This technique has a smaller incident angle of $0.2^{\circ}$ and it could obtain a more intense signal than conventional XRD from surface in order to reduce the effect of $\mathrm{Cu}$ substrate. As shown in Fig. 7, before the PEC reaction, no other peaks except copper are observed. After one hour, peaks at $2 \theta=36.4^{\circ}, 42.3^{\circ}$ and $61.4^{\circ}$ are obviously observed, which are corresponded well with $\mathrm{Cu}_{2} \mathrm{O}$ (JCPDS: 78-2076). Moreover, the peak intensity of $\mathrm{Cu}_{2} \mathrm{O}$ increases with the reaction evolution. It is demonstrated that some reactions may occur on the copper foil, leading to the formation of $\mathrm{Cu}_{2} \mathrm{O}$.

In addition, XPS technique was used to determine the variation of the copper valence. It can be clearly seen from Fig. 8(a) that nearly no change of the major elements on the copper surface is observed after the PEC reaction. As shown in Fig. 8(b), before the


Fig. 6. FE-SEM images of copper foil at various time in $\mathrm{Bi}_{2} \mathrm{MoO}_{6} / \mathrm{Cu} / \mathrm{PEC} / \mathrm{PS}$ system. Conditions: $[\mathrm{DCF}]=10 \mathrm{mg} / \mathrm{L} ; \mathrm{applied}$ bias, $1.5 \mathrm{~V}$; $[\mathrm{PS}]=5 \mathrm{mM}$; pH $\mathrm{H}_{0}, 5.62$ 


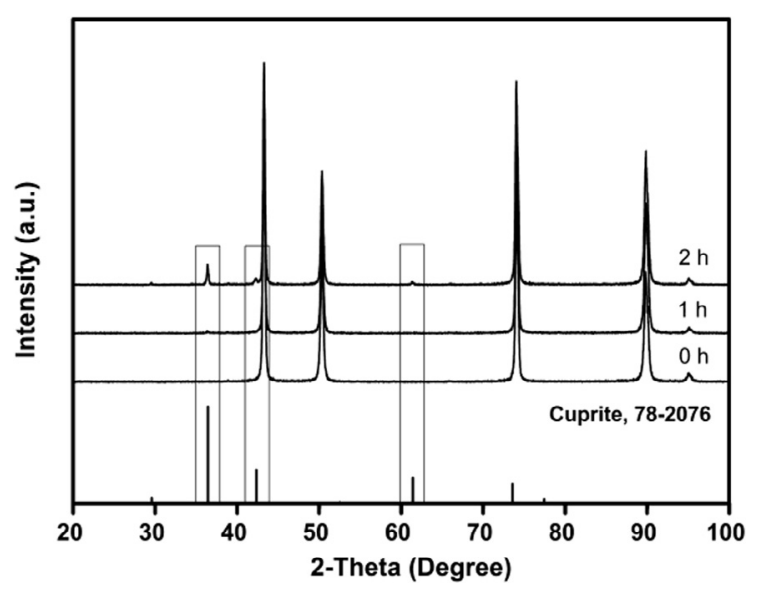

Fig. 7. GI-XRD patterns of copper foil at various times in $\mathrm{Bi}_{2} \mathrm{MoO}_{6} / \mathrm{Cu} / \mathrm{PEC} / \mathrm{PS}$ system. Conditions: $[\mathrm{DCF}]=10 \mathrm{mg} / \mathrm{L}$; applied bias, $1.5 \mathrm{~V}$; [PS] $=5 \mathrm{mM} ; \mathrm{pH}_{0}, 5.62$.


Fig. 8. XPS full scan spectra of copper cathode before and after reaction (a); XPS Cu $2 \mathrm{p}$ spectra of the copper cathode before and after reaction (b). Conditions: $[D C F]=10 \mathrm{mg} / \mathrm{L}$; applied bias, $1.5 \mathrm{~V} ;[\mathrm{PS}]=5 \mathrm{mM} ; \mathrm{pH}_{0}, 5.62$.

reaction, the major $\mathrm{Cu} 2 \mathrm{p}_{3 / 2}$ peaks centered at $932.6 \mathrm{eV}$ and major $\mathrm{Cu} 2 \mathrm{p}_{1 / 2}$ peaks centered at $952.45 \mathrm{eV}$ are assigned to zero-valent copper $[42,43]$. After the reaction, there are three peaks related to copper valence appearing in the graph. The binding energies are $933.05,952.5$ and $935.08 \mathrm{eV}$, respectively. The major $\mathrm{Cu} 2 \mathrm{p}_{3 / 2}$ peak centered at $933.05 \mathrm{eV}$ is assigned to $\mathrm{Cu}$ [44]. In addition, the major $\mathrm{Cu} 2 \mathrm{p}_{1 / 2}$ peak centered at $952.5 \mathrm{eV}$ is assigned to $\mathrm{Cu}_{2} \mathrm{O}$ [45]. Combined with XRD analysis, this evidence once again indicates that $\mathrm{Cu}(\mathrm{I})$ generates on the copper foil cathode in the PEC

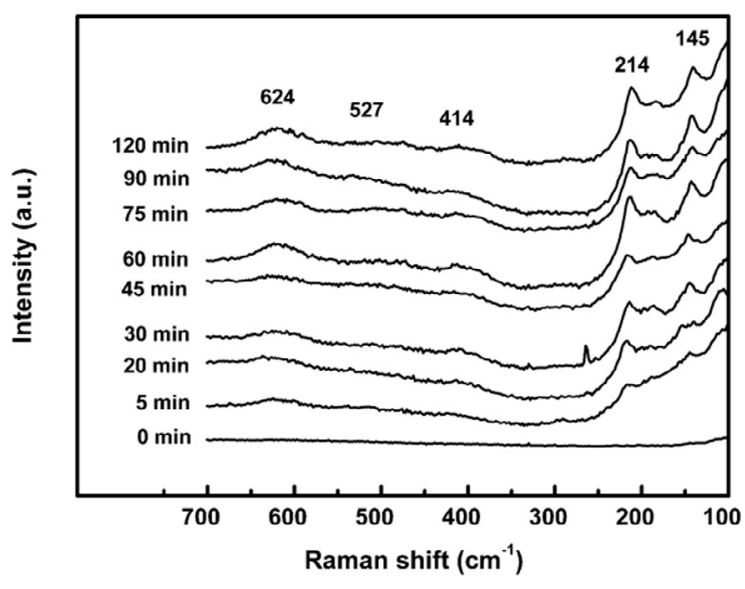

Fig. 9. In situ Raman spectroscopic analysis of the copper cathode in the PEC reaction process. Conditions: Applied bias, $1.5 \mathrm{~V}$; [PS] $=5 \mathrm{mM} ; \mathrm{pH}_{0}, 5.62$.

process. In addition, a major $\mathrm{Cu} 2 \mathrm{p}_{3 / 2}$ peak centered at $935.08 \mathrm{eV}$ is also detected and it is assigned to $\mathrm{Cu}^{2+}[46]$.

The variation of the copper foil cathode during the PEC reaction was further examined by in situ Raman spectroscopy. As shown in Fig. 9, no obvious peak is observed at $0 \mathrm{~min}$, demonstrating that the copper remains metallic. Five peaks at 145, 214, 414, 527 and $624 \mathrm{~cm}^{-1}$ appear at $5 \mathrm{~min}$, which are assigned to $\mathrm{Cu}_{2} \mathrm{O}$ [47]. The intensity of these peaks remains low before the first $30 \mathrm{~min}$ and enhances gradually from 30 min to 120 min. Besides, in situ Raman spectra of copper foil under different $\mathrm{pH}_{0}$ are compared which are shown in Fig. S5. It can be concluded that $\mathrm{pH}_{0}$ do not have an
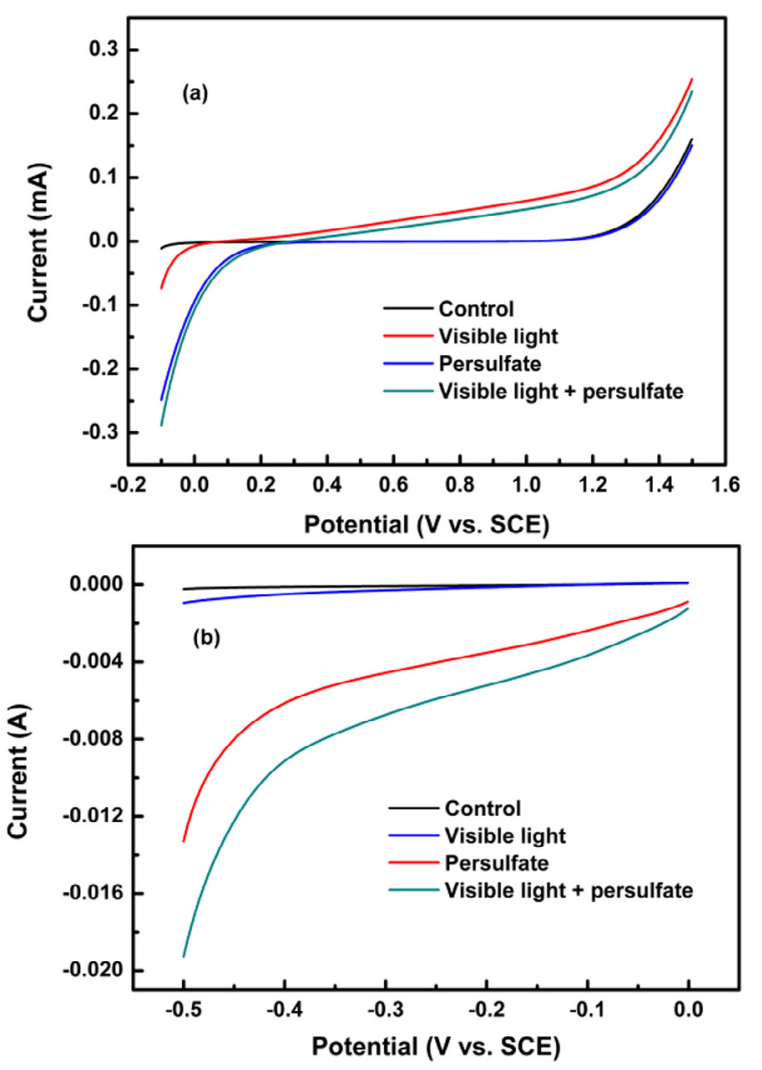

Fig. 10. LSV curves of $\mathrm{Bi}_{2} \mathrm{MoO}_{6}$ (a) and $\mathrm{Cu}_{2} \mathrm{O}$ (b) electrode in the presence and absence of visible light irradiation and persulfate in $\mathrm{Na}_{2} \mathrm{SO}_{4}$ electrolyte solution. Conditions: $[\mathrm{PS}]=5 \mathrm{mM} ;\left[\mathrm{Na}_{2} \mathrm{SO}_{4}\right]=5 \mathrm{mM} ; \lambda>420 \mathrm{~nm}$; scan rate $=10 \mathrm{mV} / \mathrm{s}$. 
obvious influence on the generation of $\mathrm{Cu}_{2} \mathrm{O}$. From above, the generation of $\mathrm{Cu}_{2} \mathrm{O}$ in the reaction process is confirmed.

\subsection{Photoelectrochemical analysis}

Photoelectrochemical characteristics of the $\mathrm{Bi}_{2} \mathrm{MoO}_{6}$ electrode and $\mathrm{Cu}_{2} \mathrm{O}$ electrode were further discussed in the presence and absence of the persulfate by LSV measurements. As shown in Fig. 10(a), under visible light irradiation, the $\mathrm{Bi}_{2} \mathrm{MoO}_{6}$ photoanode shows a significant enhancement in photocurrent response. A slight difference was observed in the presence or absence of persulfate. In Fig. 10(b), the photoelectrochemical performance of the generated $\mathrm{Cu}_{2} \mathrm{O}$ on the $\mathrm{Cu}$ cathode was presented. Under visible light irradiation, an enhancement of current is observed and the generated $\mathrm{Cu}_{2} \mathrm{O}$ shows a good response to visible light with a p-type semiconductor characterization. Furthermore, it is clear that the current is largely increased with the persulfate addition both in the dark and under visible light irradiation, which indicated the interaction between generated $\mathrm{Cu}_{2} \mathrm{O}$ and persulfate.

The IPCE plots and EIS Nyquist plots were shown in Fig. S6. IPCE increases slightly with the increase of persulfate concentration using the copper foil as cathode (Fig. S6(a)). As shown in Fig. S6(b), the arc radius of the $\mathrm{Bi}_{2} \mathrm{MoO}_{6}$ photoanode without visible light irradiation is larger than that with visible light irradiation. Smaller arc radius implies a higher efficiency of charge transfer. But the arc radius of system with persulfate is nearly similar with the system without persulfate under visible light irradiation. Above results demonstrate that the introduction of persulfate to this PEC system do not obviously change the transfer efficiency of photogenerated electron-hole pairs.

\subsection{Identification of intermediates and proposed reaction pathways}

The main intermediates of DCF in the reaction were identified by UPLC-Q-TOF-MS. A possible reaction pathway was proposed in Fig. 11. Besides DCF itself, there were four intermediates identified in the reaction (the structures were in Table S1 and the mass spectra were shown in Fig. S7). We formulated these detected products from P1 to P4, respectively. The MS spectrum of DCF shows a molecular ion peak at $294 \mathrm{~m} / \mathrm{z}$ and $250 \mathrm{~m} / \mathrm{z}$. The loss of 44 could be attributed to $\mathrm{CO}_{2}$ loss, which is consistent with previous studies about DCF. The MS spectrum of P1 shows a strong peak at $177 \mathrm{~m} / \mathrm{z}$. Previous studies reported that peak at $161 \mathrm{~m} / \mathrm{z}$ might be the major product in the degradation process of DCF [48]. P1 might be the product derived from addition reaction with $\mathrm{OH}$. In the mass spectrum of P2, the fragments are 228, 264 and $310 \mathrm{~m} / \mathrm{z}$. The most

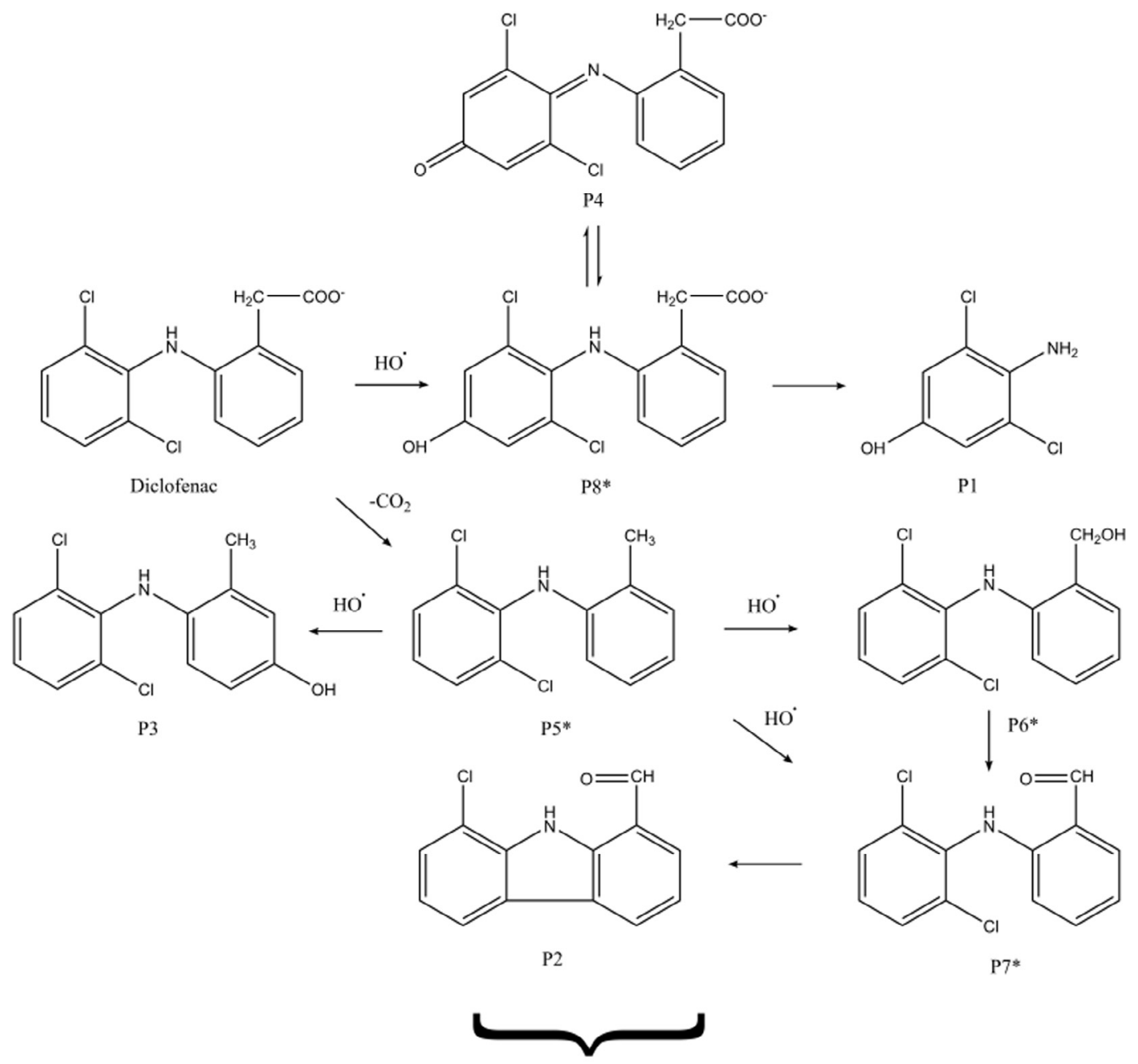

Open the ring structures

Fig. 11. Proposed degradation pathways of $D C F$ in the $\mathrm{Bi}_{2} \mathrm{MoO}_{6} / \mathrm{Cu} / \mathrm{PEC} / \mathrm{PS}$ system (intermediates with " were deduced). 
important fragment $228 \mathrm{~m} / \mathrm{z}$ corresponds to the loss of $\mathrm{HCl}$ from fragment $264 \mathrm{~m} / \mathrm{z}$. The fragment $264 \mathrm{~m} / \mathrm{z}$ corresponds to the loss of $\mathrm{OH}$ and $\mathrm{CH}_{2}$ groups from $310 \mathrm{~m} / z$. In the mass spectrum of $\mathrm{P} 3$, the most important fragment is $266 \mathrm{~m} / \mathrm{z}$ and it corresponds to the loss of $\mathrm{CO}_{2}$ from $310 \mathrm{~m} / \mathrm{z}$. P1 can be formed by cleavage of $\mathrm{C}-\mathrm{N}$ bond from P8*. There is an interchange between P4 and P8*. $\mathrm{P}^{*}$ results from decarboxylation of DCF. P3 and $\mathrm{P}^{*}$ possess the same elemental compositions and they are derived from hydroxylation as a result of $\mathrm{HO}$ attack. $\mathrm{P} 2$ is probably obtained by dehalogenation and oxidation of $\mathrm{P}^{*}$. It can be concluded that most of the identified intermediates are generated by the attack of $\mathrm{HO}$ in the reaction. This result is consistent with the ESR analyses and it is demonstrated that the main oxidizing species are $\mathrm{HO}^{-}$in this system.

\subsection{A proposed enhanced mechanism}

The above results indicated that $\mathrm{HO}^{-}$and $\mathrm{SO}_{4}^{--}$were produced from the copper foil cathode with the addition of PS; and $\mathrm{Cu}_{2} \mathrm{O}$ was generated during the PEC reaction process. Considering the above analyses, a proposed reaction process was expressed by Eqs. (6)-(9) and Scheme S1.

$\mathrm{Cu}(\mathrm{s})-\mathrm{e}^{-} \rightarrow \mathrm{Cu}^{+}(\mathrm{s})$

$\mathrm{S}_{2} \mathrm{O}_{8}^{2-}+\mathrm{e}^{-} \rightarrow \mathrm{SO}_{4}^{--}+\mathrm{SO}_{4}^{2-}$

$\mathrm{Cu}_{2} \mathrm{O}(\mathrm{s})+2 \mathrm{H}^{+} \rightarrow \mathrm{Cu}^{2+}(\mathrm{aq})+\mathrm{Cu}(\mathrm{s})+\mathrm{H}_{2} \mathrm{O}$

$\mathrm{Cu}^{2+}(\mathrm{aq})+2 \mathrm{e}^{-} \rightarrow \mathrm{Cu}(\mathrm{s})$

As illustrated in Scheme S1, PS could be activated by receiving an electron from the copper when PS was added into the PEC system. As a result, $\mathrm{SO}_{4}^{-}$and $\mathrm{HO}^{-}$were generated, which were responsible for DCF oxidation. Meanwhile, $\mathrm{Cu}_{2} \mathrm{O}$ was generated on the surface of copper cathode. In order to test its activation capacity for PS, the $\mathrm{Cu}_{2} \mathrm{O}$ thin film was prepared with an electrodeposition method on ITO glass [49]. As shown in Fig. S8, there is nearly no removal of DCF observed by the prepared $\mathrm{Cu}_{2} \mathrm{O}$ film with addition of $1 \mathrm{mM}$ PS. It is known that $\mathrm{Cu}_{2} \mathrm{O}$ is more inclined to undergo disproportionation reaction, leading to the generation of $\mathrm{Cu}$ and $\mathrm{Cu}^{2+}$ in acid conditions. $\mathrm{Cu}^{2+}$ absorbed on the surface according to XPS results may diffuse into the solution. In the meantime, $\mathrm{Cu}^{2+}$ could be deposited onto the copper surface again by cathodic reduction, which benefited the copper recycle between electrode and solution. This copper recovery process can be confirmed by the compared experiments between PEC system and chemical oxidation system in which copper just puts into solution with PS and DCF. The leached copper ion concentration in PEC system is 37\% fewer than in chemical oxidation process when the PS and copper dosage is definite. This result demonstrates that the leached copper ions can be recovered by the cathodic reduction in the PEC system. In a word, the copper surface redox cycle of $\mathrm{Cu}(0)-\mathrm{Cu}(\mathrm{I})-\mathrm{Cu}(\mathrm{II})-\mathrm{Cu}(0)$ would be probably responsible for the PS activation in this system.

\subsection{Stability analysis}

In order to evaluate the reproducibility of the system, the experiments were conducted for three times. As shown in Fig. 12, the removal efficiency of DCF does not change significantly in each cycle (67\%, $72 \%$ and $71 \%$, respectively). The final removal efficiency remains steady and consistent in the three cycles. From the above results, the system shows high reproducibility for DCF removal.

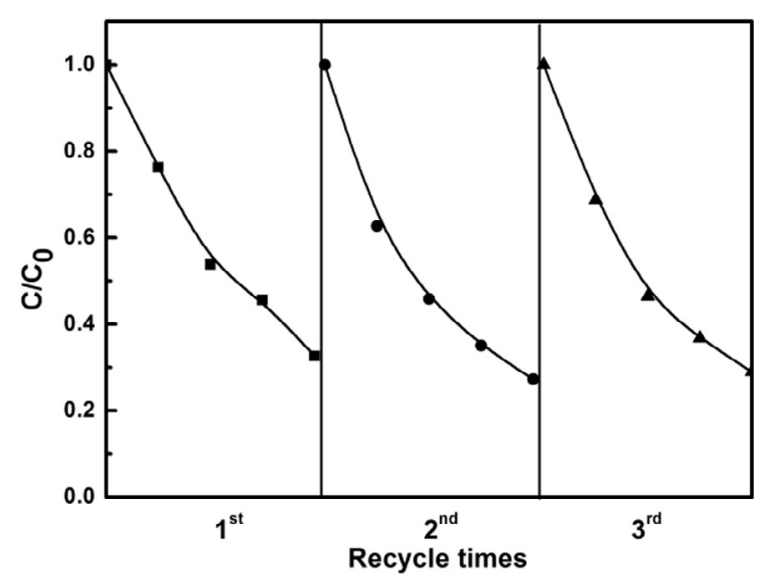

Fig. 12. The residual rate of DCF for cycles. Conditions: $[D C F]=10 \mathrm{mg} / \mathrm{L}$; applied bias, $1.5 \mathrm{~V} ;[\mathrm{PS}]=1 \mathrm{mM} ; \mathrm{pH}_{0}, 5.62$.

\section{Conclusions}

In summary, DCF can be efficiently removed in the PEC system with $\gamma-\mathrm{Bi}_{2} \mathrm{MoO}_{6}$ as photoanode and copper as cathode with the PS addition. The generation of hydroxyl radicals and sulfate radicals was detected, which was responsible for the enhanced DCF degradation. It was deduced that the copper provided electrons to PS with the generation of $\mathrm{Cu}_{2} \mathrm{O}$ on the surface and PS was activated in this process. Then $\mathrm{Cu}(\mathrm{I})$ disproportionated in the acid solution, leading to the production of $\mathrm{Cu}(0)$ and $\mathrm{Cu}(\mathrm{II}) . \mathrm{Cu}(\mathrm{II})$ was deposited onto the copper again by the cathodic reduction. Above results of this study showed the PS oxidation catalyzed with copper cathode may be an available method for contaminant removal. This work also provides a new perspective towards PS activation and efficient utilization of the cathode in the PEC system.

\section{Acknowledgements}

The authors gratefully acknowledge financial support from National Natural Science Foundation of China (No. 21377148, 51438011), Natural Science Foundation of Yongchuan, Chongqing (Ycstc, 2014ac4001).

\section{Appendix A. Supplementary data}

Supplementary data associated with this article can be found, in the online version, at http://dx.doi.org/10.1016/j.cej.2017.03.047.

\section{References}

[1] T. Heberer, Occurrence, fate, and removal of pharmaceutical residues in the aquatic environment: a review of recent research data, Toxicol. Lett. 131 (2002) 5-17.

[2] I. Kim, N. Yamashita, H. Tanaka, Photodegradation of pharmaceuticals and personal care products during UV and UV/ $\mathrm{H}_{2} \mathrm{O}_{2}$ treatments, Chemosphere 77 (2009) 518-525.

[3] W. Chen, X. Li, Z. Pan, S. Ma, L. Li, Effective mineralization of Diclofenac by catalytic ozonation using Fe-MCM-41 catalyst, Chem. Eng. J. 304 (2016) 594601.

[4] C. Martinez, M. Canle L, M.I. Fernandez, J.A. Santaballa, J. Faria, Aqueous degradation of diclofenac by heterogeneous photocatalysis using nanostructured materials, Appl. Catal. B-Environ. 107 (2011) 110-118.

[5] D. Stuelten, S. Zuehlke, M. Lamshoeft, M. Spiteller, Occurrence of diclofenac and selected metabolites in sewage effluents, Sci. Total Environ. 405 (2008) 310-316.

[6] I. Kim, H. Tanaka, Photodegradation characteristics of PPCPs in water with UV treatment, Environ. Int. 35 (2009) 793-802.

[7] D. Vogna, R. Marotta, A. Napolitano, R. Andreozzi, M. d'Ischia, Advanced oxidation of the pharmaceutical drug diclofenac with $\mathrm{UV} / \mathrm{H}_{2} \mathrm{O}_{2}$ and ozone, Water Res. 38 (2004) 414-422. 
[8] T. An, H. Sun, G. Li, H. Zhao, P.K. Wong, Differences in photoelectrocatalytic inactivation processes between E-coli and its isogenic single gene knockoff mutants: Destruction of membrane framework or associated proteins?, Appl Catal. B-Environ. 188 (2016) 360-366.

[9] X. Meng, Z. Zhang, X. Li, Synergetic photoelectrocatalytic reactors for environmental remediation: a review, J. Photochem. Photobiol. C-Photochem. Rev. 24 (2015) 83-101.

[10] H. Yu, S. Chen, X. Quan, H. Zhao, Y. Zhang, Silicon nanowire/TiO heterojunction arrays for effective photoelectrocatalysis under simulated solar light irradiation, Appl. Catal. B-Environ. 90 (2009) 242-248.

[11] X.Z. Li, H.S. Liu, Development of an $\mathrm{E}-\mathrm{H}_{2} \mathrm{O}_{2} / \mathrm{TiO}_{2}$ photoelectrocatalytic oxidation system for water and wastewater treatment, Environ. Sci. Technol 39 (2005) 4614-4620.

[12] G.P. Anipsitakis, D.D. Dionysiou, Degradation of organic contaminants in water with sulfate radicals generated by the conjunction of peroxymonosulfate with cobalt, Environ. Sci. Technol. 37 (2003) 4790-4797.

[13] H. Gao, J. Chen, Y. Zhang, X. Zhou, Sulfate radicals induced degradation of Triclosan in thermally activated persulfate system, Chem. Eng. J. 306 (2016) $522-530$.

[14] Y. Zhang, J. Zhang, Y. Xiao, V.W.C. Chang, T.-T. Lim, Kinetic and mechanistic investigation of azathioprine degradation in water by $\mathrm{UV}, \mathrm{UV} / \mathrm{H}_{2} \mathrm{O}_{2}$ and UV/persulfate, Chem. Eng. J. 302 (2016) 526-534.

[15] S.Y. Yang, P. Wang, X. Yang, G. Wei, W.Y. Zhang, L. Shan, A novel advanced oxidation process to degrade organic pollutants in wastewater: microwaveactivated persulfate oxidation, J. Environ. Sci. 21 (2009) 1175-1180.

[16] P. Drzewicz, L. Perez-Estrada, A. Alpatova, J.W. Martin, M.G. El-Din, Impact of peroxydisulfate in the presence of zero valent iron on the oxidation of cyclohexanoic acid and naphthenic acids from oil sands process-affected water, Environ. Sci. Technol. 46 (2012) 8984-8991.

[17] S. Rodriguez, L. Vasquez, D. Costa, A. Romero, A. Santos, Oxidation of Orange G by persulfate activated by $\mathrm{Fe}(\mathrm{II}), \mathrm{Fe}(\mathrm{III})$ and zero valent iron (ZVI), Chemosphere 101 (2014) 86-92.

[18] G.P. Anipsitakis, D.D. Dionysiou, Radical generation by the interaction of transition metals with common oxidants, Environ. Sci. Technol. 38 (2004) 3705-3712.

[19] C.S. Liu, K. Shih, C.X. Sun, F. Wang, Oxidative degradation of propachlor by ferrous and copper ion activated persulfate, Sci. Total Environ. 416 (2012) 507-512.

[20] T. Zhang, H. Zhu, J.-P. Croue, Production of sulfate radical from peroxymonosulfate induced by a magnetically separable $\mathrm{CuFe}_{2} \mathrm{O}_{4}$ spinel in water: efficiency, stability, and mechanism, Environ. Sci. Technol. 47 (2013) 2784-2791.

[21] Y. Lei, C.-S. Chen, Y.-J. Tu, Y.-H. Huang, H. Zhang, Heterogeneous degradation of organic pollutants by persulfate activated by $\mathrm{CuO}-\mathrm{Fe}_{3} \mathrm{O}_{4}$ : mechanism, stability, and effects of pH and bicarbonate ions, Environ. Sci. Technol. 49 (2015) 68386845.

[22] T. Zhang, Y. Chen, Y. Wang, J. Le Roux, Y. Yang, J.-P. Croue, Efficient peroxydisulfate activation process not relying on sulfate radical generation for water pollutant degradation, Environ. Sci. Technol. 48 (2014) 5868-5875.

[23] J. Fu, Y. Zhao, Q. Wu, Optimising photoelectrocatalytic oxidation of fulvic acid using response surface methodology, J. Hazard. Mater. 144 (2007) 499-505.

[24] A.A. El-Zomrawy, Kinetic studies of photoelectrocatalytic degradation of Ponceau 6R dye with ammonium persulfate, J. Saudi Chem. Soc. 17 (2013) 397-402.

[25] H. Zeng, S. Liu, B. Chai, D. Cao, Y. Wang, X. Zhao, Enhanced photoelectrocatalytic decomplexation of Cu-EDTA and $\mathrm{Cu}$ recovery by persulfate activated by UV and cathodic reduction, Environ. Sci. Technol. 50 (2016) 6459-6466.

[26] X. Zhao, J. Qu, H. Liu, C. Hu, Photoelectrocatalytic degradation of triazinecontaining azo dyes at gamma- $\mathrm{Bi}_{2} \mathrm{MoO}_{6}$ film electrode under visible light irradiation ( $\lambda>420$ nm), Environ. Sci. Technol. 41 (2007) 6802-6807.
[27] L.W. Zhang, T.G. Xu, X. Zhao, Y.F. Zhu, Controllable synthesis of $\mathrm{Bi}_{2} \mathrm{MoO}_{6}$ and effect of morphology and variation in local structure on photocatalytic activities, Appl. Catal. B-Environ. 98 (2010) 138-146.

[28] J. Tian, P. Hao, N. Wei, H. Cui, H. Liu, 3D $\mathrm{Bi}_{2} \mathrm{MoO}_{6}$ nanosheet/TiO 2 nanobelt heterostructure: enhanced photocatalytic activities and photoelectochemistry performance, ACS Catal. 5 (2015) 4530-4536.

[29] F. Liang, Y. Zhu, Enhancement of mineralization ability for phenol via synergetic effect of photoelectrocatalysis of $\mathrm{g}-\mathrm{C}_{3} \mathrm{~N}_{4}$ film, Appl. Catal. BEnviron. 180 (2016) 324-329.

[30] R. Daghrir, P. Drogui, D. Robert, Photoelectrocatalytic technologies for environmental applications, J. Photochem. Photobiol. A-Chem. 238 (2012) 41-52.

[31] C. Adams, Y. Wang, K. Loftin, M. Meyer, Removal of antibiotics from surface and distilled water in conventional water treatment processes, in: J. Environ. Eng.-ASCE 128 (2002) 253-260.

[32] G.R. Peyton, The free-radical chemistry of persulfate-based total organiccarbon analyzers, Mar. Chem. 41 (1993) 91-103.

[33] A. Ahmad, X. Gu, L. Li, S. Lu, Y. Xu, X. Guo, Effects of pH and anions on the generation of Reactive Oxygen Species (ROS) in nZVI-rGo-activated persulfate system, Water Air Soil Pollut. 226 (2015) 369.

[34] G.V. Buxton, C.L. Greenstock, W.P. Helman, A.B. Ross, Critical-review of rate constants for reactions of hydrated electrons, hydrogen-atoms and hydroxyl radicals (.OH/.O-) in aqueous-solution, J. Phys. Chem. Ref. Data 17 (1988) 513886.

[35] P. Neta, R.E. Huie, A.B. Ross, Rate constants for reactions of inorganic radicals in aqueous-solution, J. Phys. Chem. Ref. Data 17 (1988) 1027-1284.

[36] E. Hayon, A. Treinin, J. Wilf, Electronic spectra, photochemistry, and autoxidation mechanism of the sulfite-bisulfite-pyrosulfite systems. The $\mathrm{SO}_{2}^{-}, \mathrm{SO}_{3}^{-}, \mathrm{SO}_{4}^{-}$, and $\mathrm{SO}_{5}^{-}$radicals, J. Am. Chem. Soc. 94 (1972) 47-57.

[37] X. Gu, S. Lu, L. Li, Z. Qiu, Q. Sui, K. Lin, Q. Luo, Oxidation of 1,1,1-Trichloroethane stimulated by thermally activated persulfate, Ind. Eng. Chem. Res. 50 (2011) 11029-11036.

[38] X. Zhao, L. Guo, B. Zhang, H. Liu, J. Qu, Photoelectrocatalytic oxidation of Cu-IIEDTA at the $\mathrm{TiO}_{2}$ electrode and simultaneous recovery of Cu-II by electrodeposition, Environ. Sci. Technol. 47 (2013) 4480-4488.

[39] O.S. Furman, A.L. Teel, R.J. Watts, Mechanism of base activation of persulfate, Environ. Sci. Technol. 44 (2010) 6423-6428.

[40] Y. Tao, Q. Ni, M. Wei, D. Xia, X. Li, A. Xu, Metal-free activation of peroxymonosulfate by $\mathrm{g}-\mathrm{C}_{3} \mathrm{~N}_{4}$ under visible light irradiation for the degradation of organic dyes, RSC Adv. 5 (2015) 44128-44136.

[41] S. Song, L. Xu, Z. He, J. Chen, X. Xiao, B. Yan, Mechanism of the photocatalytic degradation of C.I. Reactive Black 5 at pH 12.0 using $\mathrm{SrTiO}_{3} / \mathrm{CeO}_{2}$ as the catalyst, Environ. Sci. Technol. 41 (2007) 5846-5853.

[42] C.D. Wagner, Chemical shifts of Auger lines, and the Auger parameter, Faraday Discuss. Chem. Soc. 60 (1975) 291-300.

[43] A.C. Miller, G.W. Simmons, Copper by XPS, Surf. Sci. Spectra 2 (1993) 55-60.

[44] J. Haber, T. Machej, L. Ungier, J. Ziolkowski, ESCA studies of copper oxides and copper molybdates, J. Solid State Chem. 25 (1978) 207-218.

[45] J.G. Jolley, G.G. Geesey, M.R. Hankins, R.B. Wright, P.L. Wichlacz, Auger electron and X-ray photoelectron spectroscopic study of the biocorrosion of copper by alginic acid polysaccharide, Appl. Surf. Sci. 37 (1989) 469-480.

[46] R.P. Vasquez, $\mathrm{CuCl}_{2}$ by XPS, Surf. Sci. Spectra 2 (1993) 160-164.

[47] D. Ren, Y. Deng, A.D. Handoko, C.S. Chen, S. Malkhandi, B.S. Yeo, Selective electrochemical reduction of carbon dioxide to ethylene and ethanol on copper (I) oxide catalysts, ACS Catal. 5 (2015) 2814-2821.

[48] H. Cheng, D. Song, H. Liu, J. Qu, Permanganate oxidation of diclofenac: the $\mathrm{pH}$-dependent reaction kinetics and a ring-opening mechanism, Chemosphere 136 (2015) 297-304.

[49] P. Wang, H. Wu, Y.M. Tang, R. Amal, Y.H. Ng, Electrodeposited $\mathrm{Cu}_{2} \mathrm{O}$ as photoelectrodes with controllable conductivity type for solar energy conversion, J. Phys. Chem. C 119 (2015) 26275-26282. 